Article

\title{
Effects of Organic Acids, Amino Acids and Phenolic Compounds on Antioxidant Characteristic of Zhenjiang Aromatic Vinegar
}

\author{
Bo Zhang ${ }^{\dagger}$, Ting Xia ${ }^{\dagger}$, Wenhui Duan, Zhujun Zhang, Yu Li, Bin Fang, Menglei Xia and \\ Min Wang *iD
}

State Key Laboratory of Food Nutrition and Safety, Key Laboratory of Industrial Fermentation Microbiology, College of Biotechnology, Tianjin University of Science and Technology, Tianjin 300222, China; bozhango@163.com (B.Z.); xiatingsyu@foxmail.com (T.X.); duanwhyy@163.com (W.D.); yzhujunz@126.com (Z.Z.); liyu962366@163.com (Y.L.); ab1772850431@163.com (B.F.); mlxia@tust.edu.cn (M.X.)

* Correspondence: minw@tust.edu.cn; Tel.: +86-22-6060-1256

+ These authors contributed equally to this paper.

Academic Editor: Gianni Sacchetti

Received: 28 September 2019; Accepted: 19 October 2019; Published: 22 October 2019

\begin{abstract}
Zhenjiang aromatic vinegar (ZAV) is one of the famous Chinese vinegars, which contains various physicochemical and bioactive compositions. In the present study, physicochemical properties and total antioxidant activity were detected in ZAV samples. The correlation between of organic acids, amino acids, phenolic compounds, and the antioxidant activity of ZAV were explored. The results showed that contents of total acids, soluble solids, reducing sugar and total antioxidant activity in ZAV were increased with aging time, and those in ZAV-5 were the highest. Organic acids and amino acids exhibited weak antioxidant activity, while phenolic compounds had higher antioxidant ability. In addition, amino acids had synergistic effect on the antioxidant activity of phenolic compounds, whereas organic acids inhibited the antioxidant activity of phenolic compounds. Moreover, it was found that phenolic compounds including catechin, vanillic acid and syringic acid showed higher contribution rates to antioxidant activities of mixed phenolic compounds. In conclusion, these findings would provide references to control the antioxidant characteristic of vinegar through regulating the main compositions, and further improve the quality of vinegar production.
\end{abstract}

Keywords: Zhenjiang aromatic vinegar; organic acids; amino acids; phenolic compounds; antioxidant activity; synergistic effect

\section{Introduction}

Vinegar has been used as acidic condiment all over the world for more than three thousand years [1]. Traditional vinegars were brewed from different raw materials such as fruits and grains by spontaneous fermentation technology [2,3]. Zhenjiang aromatic vinegar (ZAV), one of the most famous vinegars in China, is produced by solid-state fermentation [4]. Raw materials of ZAV include rice, wheat bran and rice hulls. The brewing process of ZAV is mainly divided into five stages: alcoholic fermentation (AF), acetic acid fermentation (AAF), leaching, decoction and aging stage [5]. During the process, it produces many chemical compositions such as organic acids, amino acids, sugars and other bioactive compounds, which have benefit effects on human health [6-9].

Vinegars contain abundant organic acids, which are the main source of vinegar flavor and important indictors to evaluate the quality of vinegar [10]. They can be divided into volatile and non-volatile acids. Volatile organic acids include acetic acid, formic acid, propionic acid, butyric acid and quinic acid, etc., [11,12]. It has been reported that acetic acid is the most abundant organic acid in 
vinegar, accounting for about half of the total organic acids [13]. In addition, there are a large number of non-volatile acids such as lactic acid, malic acid, pyroglutamic acid, citric acid and succinic acid [14,15]. These non-volatile acids buffer the stimulation of acetic acid and contribute to the strong aroma and flavor [13].

Amino acids in vinegars including free amino acids and nonprotein amino acids, come from raw materials and microbial decomposition during the fermentation and aging processes [16-18]. Amino acids can provide different taste to vinegars such as umami, sweet and bitter [19]. Amino acids are essential nutrients, which play important roles to human health [20]. Some amino acids including lysine, histidine and arginine react with sugars and produce melanoidins, which have antioxidant activity [17]. Otherwise, sulfur-containing amino acids such as methionine and cysteine can be converted into reduced glutathione through redox cycle, which subsequently protect against oxidative damage [21]. Aromatic amino acids including tryptophan, tyrosine and phenylalanine inhibit chain reaction of free radical and have antioxidant effect [22].

Phenolic compounds are major bioactive ingredients in vinegars, which mainly derived from raw materials [23]. These phenolic compounds contain one or more phenolic hydroxyl groups on the aromatic ring and play an important role in the antioxidant activity [24,25]. Recent studies have reported that the antioxidant activity of vinegars has positive correlation with polyphenolic fraction [26-28]. Bakir et al. [29] reported that antioxidant activities of grape and apple vinegars range from $254 \pm 8 \mathrm{mg}$ TEAC/100 mL to $568 \pm 76 \mathrm{mg}$ TEAC/100 mL by ferric reducing antioxidant power (FRAP) assay and from $418 \pm 49 \mathrm{mg}$ TEAC/100 mL to $2561 \pm 260 \mathrm{mg}$ TEAC/100 mL by 2,2' -azino-bis(3-ethylbenzthi azoline-6-sulfonic acid) (ABTS) assay, respectively. The phenolic compounds in these vinegars were detected including gallic acid, $p$-hydroxybenzoic acid, catechin, syringic acid, caffeic acid and $p$-coumaric acid. Verzelloni et al. [30] found that the antioxidant capacity of red wines and traditional balsamic vinegars was highly correlated with their phenolic and flavonoid contents. The compounds contained catechin, epigallocatechin galate (EGCG), quercetin, cinnamic acid, gallic acid and resveratrol. In a previous study, we found that the antioxidant capacity of Shanxi aged vinegar was highly correlated with their polyphenol contents. There were eight phenolic compounds in Shanxi aged vinegar determined by high performance liquid chromatography (HPLC) [31]. However, the major compositions and their contribution to antioxidant activities of ZAV have been rarely explored.

The aim of this study is to elucidate the antioxidant properties of ZAV and their potentially correlated with the main chemical compositions. In this study, the contents of physicochemical components, organic acids, amino acids and polyphenols were detected in ZAV. In addition, the antioxidant activities of ZAV and major compounds including organic acids, amino acids and polyphenols were evaluated by different methods. Moreover, the relationship between these main chemical compositions and the antioxidant properties of ZAV was investigated.

\section{Results and Discussion}

\subsection{Physicochemical Parameters in ZAV}

Physicochemical parameters of ZAV were shown in Table 1. $\mathrm{pH}$ values in all vinegar samples ranged from $3.28 \pm 0.02$ to $3.46 \pm 0.01$. The total acids contents ranged between $4.954 \pm 0.221$ and $7.726 \pm 0.017 \mathrm{~g} / 100 \mathrm{~mL}$, which were increased with the aging time. Kim et al. [32] reported that $\mathrm{pH}$ and total acids contents of commercial vinegar in Korea were $2.81 \sim 3.20$ and $2.07 \pm 0.03 \sim 2.42 \pm 0.02 \mathrm{~g} / 100 \mathrm{~mL}$, respectively. Xia et al. [27] reported that the total acids content was $3.5 \sim 8.0 \mathrm{~g} / 100 \mathrm{~mL}$ in Shanxi aged vinegar. By comparing the data of total acids contents in different types of vinegars, total acids content of ZAV is higher than that in Korean vinegar, and similar to that in Shanxi aged vinegar. In addition, contents of non-volatile acids in ZAV ranged from $1.769 \pm 0.057$ to $2.388 \pm 0.089 \mathrm{~g} / 100 \mathrm{~mL}$, which were increased during six years of aging time and then decreased gradually. Non-volatile acids and reducing sugar can buffer the stimulation of acetic acid and improve the taste and flavor of vinegar [13]. Reducing sugar contents ranged between $1.450 \pm 0.071$ and $2.850 \pm 0.212 \mathrm{~g} / 100 \mathrm{~mL}$, 
which were positively associated with aging time. The contents of soluble solids in the samples were $12.738 \pm 0.084 \sim 19.428 \pm 0.005 \mathrm{~g} / 100 \mathrm{~mL}$, and elevated with the aging time. Amino nitrogen is content of nitrogen existed as amino acids, which is a characteristic index to determine the fermented degree in the products [17]. The results showed that content of amino nitrogen in the samples ranged between $0.399 \pm 0.002$ and $0.468 \pm 0.021 \mathrm{~g} / 100 \mathrm{~mL}$, which decreased slightly during three years of aging time and then increased with the aging time. Collectively, the contents of total acids, soluble solids and reducing sugar were increased with aging time, which were the highest in ZAV-5.

Table 1. Physicochemical parameters of Zhenjiang aromatic vinegar (ZAV) ${ }^{1,2}$.

\begin{tabular}{ccccccc}
\hline $\begin{array}{c}\text { Sample } \\
\text { Number }\end{array}$ & $\mathbf{p H}$ & $\begin{array}{c}\text { Total Acids } \\
(\mathrm{g} / \mathbf{1 0 0 m L})\end{array}$ & $\begin{array}{c}\text { Non-Volatile } \\
\text { Acids } \\
(\mathbf{g} / \mathbf{1 0 0 m L})\end{array}$ & $\begin{array}{c}\text { Reducing } \\
\text { Sugar } \\
(\mathbf{g} / \mathbf{1 0 0 m L})\end{array}$ & $\begin{array}{c}\text { Soluble Solids } \\
(\mathbf{g} / \mathbf{1 0 0 m L})\end{array}$ & $\begin{array}{c}\text { Amino } \\
\text { Nitrogen } \\
(\mathbf{g} / \mathbf{1 0 0 m L})\end{array}$ \\
\hline ZAV-1 & $3.46 \pm 0.01 \mathrm{a}$ & $4.954 \pm 0.221 \mathrm{e}$ & $1.769 \pm 0.057 \mathrm{e}$ & $1.500 \pm 0.183 \mathrm{c}$ & $12.738 \pm 0.084 \mathrm{~d}$ & $0.399 \pm 0.002 \mathrm{c}$ \\
ZAV-2 & $3.28 \pm 0.02 \mathrm{e}$ & $6.192 \pm 0.161 \mathrm{~d}$ & $2.300 \pm 0.074 \mathrm{~b}$ & $1.450 \pm 0.071 \mathrm{c}$ & $13.616 \pm 0.011 \mathrm{c}$ & $0.344 \pm 0.010 \mathrm{e}$ \\
ZAV-3 & $3.34 \pm 0.02 \mathrm{~d}$ & $6.251 \pm 0.122 \mathrm{c}$ & $2.388 \pm 0.089 \mathrm{a}$ & $2.050 \pm 0.071 \mathrm{~b}$ & $16.602 \pm 0.071 \mathrm{~b}$ & $0.385 \pm 0.007 \mathrm{~d}$ \\
ZAV-4 & $3.41 \pm 0.01 \mathrm{~b}$ & $6.664 \pm 0.078 \mathrm{~b}$ & $2.079 \pm 0.022 \mathrm{c}$ & $2.000 \pm 0.141 \mathrm{~b}$ & $16.588 \pm 0.022 \mathrm{~b}$ & $0.427 \pm 0.017 \mathrm{~b}$ \\
ZAV-5 & $3.36 \pm 0.02 \mathrm{c}$ & $7.726 \pm 0.017 \mathrm{a}$ & $1.858 \pm 0.011 \mathrm{~d}$ & $2.850 \pm 0.212 \mathrm{a}$ & $19.428 \pm 0.005 \mathrm{a}$ & $0.468 \pm 0.021 \mathrm{a}$ \\
\hline
\end{tabular}

${ }^{1}$ Data are presented as mean \pm S.D. $(n=3) .{ }^{2}$ Significant differences are evaluated using the Duncan Multiple comparison Test. Different letters in the column presents statistically significant differences $(p<0.05)$.

\subsection{Analysis of Total Antioxidant Activity in ZAV}

Total antioxidant activities of ZAV in different samples were measured by DPPH, ABTS and FRAP methods. As shown in Figure 1, the values of antioxidant activity ZAV were $16.876 \pm 1.384$ $33.172 \pm 3.703 \mathrm{mmol}$ TEAC/L (2,2-diphenyl-1-picrylhydrazyl (DPPH) assay), $24.032 \pm 2.650$ $35.608 \pm 2.481 \mathrm{mmol}$ TEAC/L (ABTS assay) and $26.635 \pm 1.654 \sim 38.844 \pm 2.282 \mathrm{mmol}$ TEAC/L (FRAP assay), respectively. These values were followed in decreasing order: ZAV-5 $>$ ZAV-4 $>$ ZAV-3 $>$ ZAV-2 $>$ ZAV-1. Bertelli et al. [33] reported that the antioxidant activities of traditional balsamic vinegar from Modena ( $>25$ years of aging) were $19.61 \pm 14.0 \mu \mathrm{M}$ TEs/mL by DPPH and $33.04 \pm 21.8 \mu \mathrm{M}$ TEs $/ \mathrm{mL}$ by ABTS. The antioxidant activities of Shanxi aged vinegar in different aging time ranged from $8.13 \pm 0.29$ mmol TEAC/L to $22.11 \pm 1.53 \mathrm{mmol} \mathrm{TEAC/L}$ by FRAP and $6.10 \pm 0.62 \mathrm{mmol}$ TEAC/L to $29.94 \pm 0.58$ mmol of TEAC/L by ABTS, respectively, which were increased with the aging time [31]. In this study, ZAV showed similar trends compared with previous studies, and total antioxidant activity of ZAV-5 was the highest in all vinegar samples.

A

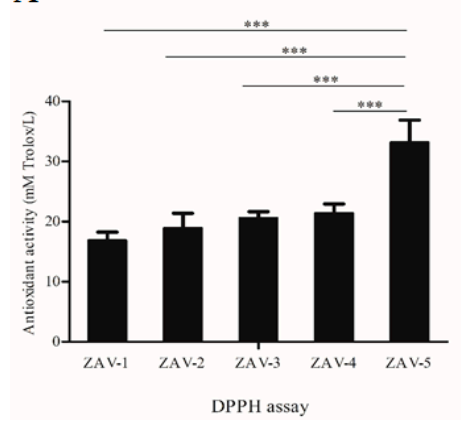

B

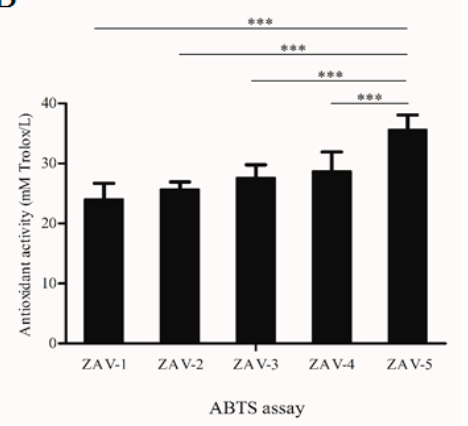

$\mathrm{C}$

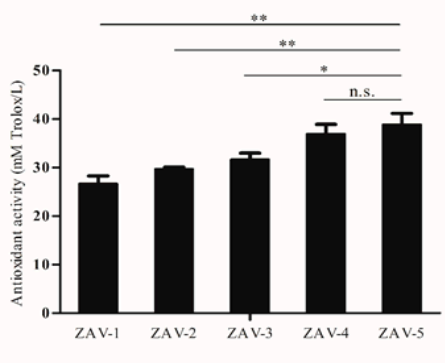

FRAP assay

Figure 1. Total antioxidant activity of Zhenjiang aromatic vinegar (ZAV) measured by three different assays. (A) DPPH assay, (B) ABTS assay, (C) FRAP assay. All data are expressed as mean \pm S.D. $(n=6)$. ${ }^{*} p<0.05,{ }^{* *} p<0.01,{ }^{* * *} p<0.001$ vs. ZAV-5, n.s. indicates no significant difference.

\subsection{Organic Acids Contents and Antioxidant Activities in ZAV-5}

Then, we focused on the principal component in ZAV-5. Vinegars contain abundant organic acids, which mainly come from brewing raw materials [17]. Organic acids in ZAV-5 were presented in Table 2. It was found that 7 organic acids in ZAV-5 were identified by HPLC. Among these organic acids, the 
content of acetic acid was $6.606 \pm 0.352 \mathrm{~g} / 100 \mathrm{~mL}$, was the highest in ZAV-5. In addition, the contents of lactic acid and pyroglutamic acid were $3.283 \pm 0.241$ and $1.363 \pm 0.255 \mathrm{~g} / 100 \mathrm{~mL}$, respectively, indicating the major non-volatile acids in ZAV-5. Meanwhile, total contents of non-volatile acids in ZAV-5 accounted for about $85.85 \%$ of acetic acid content. Zhu et al. [10] reported that 10 kinds of organic acids were identified in Shanxi aged vinegar by ion liquid chromatography (IC). Among these organic acids, the content of acetic acid was the highest in volatile acids, which ranged from $45945.9 \mathrm{mg} / \mathrm{L}$ to $87723.5 \mathrm{mg} / \mathrm{L}$. Lactic acid content was the largest in nonvolatile acid, which varied between $2575.7 \mathrm{mg} / \mathrm{L}$ and $30336.6 \mathrm{mg} / \mathrm{L}$. Lalou et al. [34] found that acetic acid, formic acid, citric acid, malic acid and succinic acid in balsamic vinegar were identified by nuclear magnetic resonance (NMR) method. The amount of acetic acid was $28.52 \pm 2.14 \sim 63.57 \pm 5.80 \mathrm{~g} / \mathrm{kg}$, followed by malic acid $(1.34 \pm 0.054 \sim 8.59 \pm 0.438 \mathrm{~g} / \mathrm{kg})$ and citric acid $(0.29 \pm 0.008 \sim 2.90 \pm 0.123 \mathrm{~g} / \mathrm{kg})$. By comparison of organic acids in different types of vinegars, acetic acid as a kind of volatile acid is the major organic acid in vinegars, which contributes the primary flavor of vinegars. The kinds and contents of non-volatile acids are different in various vinegars, which may associate with different raw materials and fermentation technologies during manufacturing process.

Table 2. Organic acid contents and antioxidant activities in ZAV-5 1,2,3.

\begin{tabular}{ccccc}
\hline \multirow{2}{*}{ Organic Acids } & Contents $(\mathbf{g} / \mathbf{1 0 0} \mathbf{~ m L})$ & \multicolumn{3}{c}{ Antioxidant Activities (mmol TEAC/g) } \\
\cline { 3 - 5 } & & DPPH & ABTS & FRAP \\
\hline Oxalic acid & $0.188 \pm 0.011 \mathrm{f}$ & $0.003 \pm 0.000 \mathrm{a}$ & ND & $0.007 \pm 0.000 \mathrm{~b}$ \\
Acetic acid & $6.606 \pm 0.352 \mathrm{a}$ & $0.001 \pm 0.000 \mathrm{~b}$ & ND & $0.002 \pm 0.000 \mathrm{~d}$ \\
Tartaric acid & $0.091 \pm 0.001 \mathrm{~g}$ & ND & ND & $0.003 \pm 0.000 \mathrm{c}$ \\
Succinic acid & $0.529 \pm 0.045 \mathrm{~d}$ & ND & ND & $0.002 \pm 0.000 \mathrm{~d}$ \\
Malic acid & $0.217 \pm 0.016 \mathrm{e}$ & ND & ND & $0.003 \pm 0.000 \mathrm{c}$ \\
Pyroglutamic acid & $1.363 \pm 0.255 \mathrm{c}$ & ND & ND & $0.003 \pm 0.000 \mathrm{c}$ \\
Lactic acid & $3.283 \pm 0.241 \mathrm{~b}$ & ND & ND & $0.008 \pm 0.000 \mathrm{a}$ \\
\hline
\end{tabular}

\footnotetext{
${ }^{1}$ Data are presented as mean \pm S.D. $(n=3) .{ }^{2}$ Significant differences are evaluated using the Duncan Multiple comparison Test. Different letters in the column presents statistically significant differences $(p<0.05) .{ }^{3}$ ND represents not detectable.
}

To explore the relationship between the main ingredients and antioxidant activities in ZAV-5, the antioxidant activity values of organic acids were evaluated by DPPH, ABTS and FRAP. These results showed that all organic acids exhibited weak iron reducing capacity, but were not detected in ABTS assay. Acetic acid and oxalic acid showed weak DPPH scavenging ability, and the rest organic acids were not detected in DPPH assay (Table 2). These results indicate that organic acids exhibit very low contribution to total antioxidant activity of ZAV-5.

\subsection{Amino Acids Contents and Antioxidant Activities in ZAV-5}

As shown in Table 3, amino acids in ZAV-5 were detected by amino acid analyzer. The content of leucine $(1.535 \pm 0.028 \mathrm{~g} / \mathrm{L})$ was the highest among all amino acids, followed by glycine $(1.444 \pm 0.221 \mathrm{~g} / \mathrm{L})$ and threonine $(1.411 \pm 0.324 \mathrm{~g} / \mathrm{L})$, respectively. These amino acids were mainly contributed to sweet and fresh taste of ZAV. Additionally, essential amino acids accounted for about $61.52 \%$ of total amino acids in ZAV. These amino acids are essential nutrients to human body, which have beneficial effects such as improving immunity and promoting brain development [7,20]. It has been reported that the content of alanine in Shanxi aged vinegar was in the range of $1328.96 \pm 6.13 \sim 2990.49 \pm 42.56 \mu \mathrm{g} / \mathrm{mL}$, which was the highest amino acids. Leucine $(699.23 \pm 6.57 \sim 1832.29 \pm 11.82 \mu \mathrm{g} / \mathrm{mL})$ and glutamic acid $(92.55 \pm 3.59 \sim 1635.48 \pm 29.26 \mu \mathrm{g} / \mathrm{mL})$ were the other two major amino acids [27]. In a study conducted by Chinnici et al. [35] who studied amino acids in traditional balsamic vinegar (TBV), balsamic vinegar and sherry vinegar. It was found that proline was the highest content $(494.67 \mathrm{mg} / \mathrm{kg}, 98.8 \mathrm{mg} / \mathrm{kg}$ and $308.56 \mathrm{mg} / \mathrm{kg}$ ) in three types of vinegars. According to previous studies, the contents of amino acids in 
various vinegars were different related to raw materials and production process. Among these amino acids, leucine, glycine and threonine were the main amino acids in ZAV-5.

Table 3. Amino acids contents and antioxidant activities in ZAV-5 1,2,3.

\begin{tabular}{ccccc}
\hline \multirow{2}{*}{ Amino Acids } & Contents $(\mathrm{g} / \mathrm{L})$ & \multicolumn{2}{c}{ Antioxidant Activities (mmol TEAC/g) } \\
\cline { 3 - 5 } & & DPPH & ABTS & FRAP \\
\hline Phenylalanine & $0.501 \pm 0.033 \mathrm{f}$ & $0.127 \pm 0.015 \mathrm{a}$ & $0.123 \pm 0.029 \mathrm{a}$ & $0.177 \pm 0.015 \mathrm{a}$ \\
Lysine & $0.466 \pm 0.024 \mathrm{~g}$ & $0.012 \pm 0.003 \mathrm{~b}$ & $0.077 \pm 0.007 \mathrm{~b}$ & $0.022 \pm 0.003 \mathrm{~b}$ \\
Tyrosine & $0.287 \pm 0.015 \mathrm{~h}$ & $0.008 \pm 0.001 \mathrm{c}$ & $0.015 \pm 0.008 \mathrm{c}$ & $0.013 \pm 0.002 \mathrm{c}$ \\
Arginine & $0.161 \pm 0.002 \mathrm{i}$ & ND & $0.010 \pm 0.002 \mathrm{c}$ & $0.006 \pm 0.000 \mathrm{~d}$ \\
Valine & $0.892 \pm 0.041 \mathrm{c}$ & ND & ND & $0.005 \pm 0.000 \mathrm{e}$ \\
Isoleucine & $0.672 \pm 0.051 \mathrm{e}$ & ND & ND & $0.006 \pm 0.000 \mathrm{~d}$ \\
Leucine & $1.535 \pm 0.028 \mathrm{a}$ & ND & ND & $0.006 \pm 0.000 \mathrm{~d}$ \\
Threonine & $1.411 \pm 0.324 \mathrm{~b}$ & ND & ND & $0.005 \pm 0.000 \mathrm{e}$ \\
Histidine & $0.862 \pm 0.079 \mathrm{c}$ & ND & ND & $0.006 \pm 0.000 \mathrm{~d}$ \\
Alanine & $0.775 \pm 0.092 \mathrm{~d}$ & ND & ND & $0.006 \pm 0.000 \mathrm{~d}$ \\
Glycine & $1.444 \pm 0.221 \mathrm{~b}$ & ND & ND & $0.006 \pm 0.001 \mathrm{~d}$ \\
Methionine & $0.166 \pm 0.011 \mathrm{i}$ & ND & ND & $0.006 \pm 0.000 \mathrm{~d}$ \\
\hline
\end{tabular}

$1 \overline{\text { Data are presented as mean } \pm \text { S.D. }(n=3) .{ }^{2} \text { Significant differences are evaluated using the Duncan Multiple }}$ comparison Test. Different letters in the column presents statistically significant differences $(p<0.05) .{ }^{3}$ ND represents not detectable.

Then, the antioxidant activities of amino acids in ZAV-5 were detected by DPPH, ABTS and FRAP. The results showed that phenylalanine, tyrosine and lysine had low DPPH and ABTS radicals scavenging ability and iron reducing ability. Arginine had weak scavenging ability and iron reducing ability. However, the rest amino acids had very faint iron reducing ability, and were not examined by DPPH and ABTS. The data imply that amino acids contribute weakly to total antioxidant activity of ZAV-5.

\subsection{Phenolic Compounds Contents and Antioxidant Activities in ZAV-5}

The polyphenols in ZAV-5 were determined by HPLC (Table 4). The results showed that 11 polyphenols were detected in ZAV-5. Among these polyphenols, the content of catechin $(36.745 \pm 1.459 \mathrm{mg} / \mathrm{L})$ was highest, followed by $p$-hydroxybenzoic acid $(24.738 \pm 2.376 \mathrm{mg} / \mathrm{L})$ and vanillic acid $(15.223 \pm 3.892 \mathrm{mg} / \mathrm{L})$ in ZAV-5. Previous study reported that gallic acid $(114.67 \pm 3.88 \mathrm{mg} / \mathrm{L})$, catechins $(86.98 \pm 0.36 \mathrm{mg} / \mathrm{L})$ and caffeic acid $(53.69 \pm 1.87 \mathrm{mg} / \mathrm{L})$ were the main phenolic compounds in Shanxi aged vinegar [31]. Kharchoufi et al. [36] reported that there were 17 phenolic compounds in pomegranate vinegar determined by ultra-performance liquid chromatography-mass spectrum (UPLC-MS). The content of protocatechuic acid $(28.88 \pm 0.02 \mathrm{mg} / \mathrm{L})$ was highest, followed by gallic acid. In this study, the content of gallic acid was $0.981 \pm 0.092 \mathrm{mg} / \mathrm{L}$, which were not different from other studies. Taken together, these results indicate that catechin, $p$-hydroxybenzoic acid and vanillic acid were the major phenolic compounds in ZAV-5.

The antioxidant activities of phenolic compounds were showed in Table 4. It was found that the values of antioxidant activities in DPPH method were followed by caffeic acid, gallic acid, catechin, sinapic acid, syringic acid, ferulic acid and rutin, which had high antioxidant activity. According to ABTS assay, gallic acid had the highest antioxidant activity, which was not directly proportional to the content, followed by catechin, rutin, ferulic acid, syringic acid, sinapic acid and caffeic acid. The antioxidant activity values of rutin and gallic acid were higher than others, and as follows in decreasing order: rutin $>$ gallic acid $>$ syringic acid $>$ caffeic acid $>$ ferulic acid $>$ sinapic acid $>$ catechin . However, vanillic acid, $p$-coumaric acid and $p$-hydroxybenzoic acid had very low antioxidant activity (FRAP assay). Taken together, the results suggest that polyphenols including caffeic acid, gallic acid, sinapic acid, syringic acid, catechin, rutin and ferulic acid exhibit high antioxidant activity in ZAV-5. 
Table 4. Phenolic compounds contents and antioxidant activities in ZAV-5 1,2,3.

\begin{tabular}{ccccc}
\hline \multirow{2}{*}{ Phenolic Compounds } & Contents $(\mathrm{mg} / \mathrm{L})$ & \multicolumn{2}{c}{ Antioxidant Activities (mmol TEAC/g) } \\
\cline { 3 - 5 } & & DPPH & ABTS & FRAP \\
\hline Caffeic acid & $2.722 \pm 0.014 \mathrm{e}$ & $3.323 \pm 0.407 \mathrm{a}$ & $1.708 \pm 0.757 \mathrm{~d}$ & $2.507 \pm 0.156 \mathrm{~d}$ \\
Gallic acid & $0.981 \pm 0.092 \mathrm{j}$ & $3.197 \pm 0.186 \mathrm{~b}$ & $3.174 \pm 0.214 \mathrm{a}$ & $4.436 \pm 0.548 \mathrm{~b}$ \\
Sinapic acid & $1.383 \pm 0.251 \mathrm{i}$ & $2.414 \pm 0.478 \mathrm{c}$ & $2.134 \pm 0.528 \mathrm{c}$ & $2.370 \pm 0.128 \mathrm{e}$ \\
Syringic acid & $2.123 \pm 0.009 \mathrm{f}$ & $2.298 \pm 0.100 \mathrm{~d}$ & $2.241 \pm 0.721 \mathrm{c}$ & $3.285 \pm 0.399 \mathrm{c}$ \\
Catechin & $36.745 \pm 1.459 \mathrm{a}$ & $2.543 \pm 0.136 \mathrm{c}$ & $2.620 \pm 0.393 \mathrm{~b}$ & $1.266 \pm 0.250 \mathrm{f}$ \\
Rutin & $1.812 \pm 0.142 \mathrm{~g}$ & $2.028 \pm 0.278 \mathrm{e}$ & $2.575 \pm 0.082 \mathrm{~b}$ & $5.094 \pm 0.237 \mathrm{a}$ \\
Ferulic acid & $1.575 \pm 0.172 \mathrm{~h}$ & $2.262 \pm 0.200 \mathrm{~d}$ & $2.522 \pm 0.700 \mathrm{~b}$ & $2.440 \pm 0.230 \mathrm{e}$ \\
Chlorogenic acid & $6.125 \pm 0.912 \mathrm{~d}$ & $0.291 \pm 0.012 \mathrm{f}$ & $0.374 \pm 0.004 \mathrm{e}$ & $0.524 \pm 0.001 \mathrm{~g}$ \\
$P$-hydroxybenzoic acid & $24.738 \pm 2.376 \mathrm{~b}$ & $0.046 \pm 0.004 \mathrm{~g}$ & $\mathrm{ND}$ & ND \\
Vanillic acid & $15.223 \pm 3.892 \mathrm{c}$ & $0.029 \pm 0.004 \mathrm{~h}$ & $0.233 \pm 0.009 \mathrm{f}$ & $0.460 \pm 0.078 \mathrm{~h}$ \\
$P$-coumaric acid & $1.651 \pm 0.224 \mathrm{~h}$ & $0.027 \pm 0.011 \mathrm{~h}$ & $0.370 \pm 0.046 \mathrm{e}$ & $0.421 \pm 0.003 \mathrm{i}$ \\
\hline
\end{tabular}

${ }^{1}$ Data are presented as mean \pm S.D. $(n=3) .{ }^{2}$ Significant differences are evaluated using the Duncan Multiple comparison Test. Different letters in the column presents statistically significant differences $(p<0.05) .{ }^{3}$ ND represents not detectable.

\subsection{Effects of Main Components on Antioxidant Activities of ZAV-5}

To investigate the effects of the main components on the antioxidant activities in ZAV-5, organic acids, amino acids and phenolic compounds were mixed and determined by DPPH, ABTS and FRAP. As shown in Table 5, the antioxidant activities of organic acid solution were very low in FRAP assay, but not be detected in DPPH and ABTS assay. The antioxidant activity of phenolic compounds was significant higher than amino acids and organic acids. When organic acids and phenolic compounds were mixed, antioxidant activities of the mixture were lower than antioxidant activities of phenolic compounds alone. The results suggest that organic acids have antagonistic effect on the antioxidant capacity of phenolic compounds. When organic acids, amino acids and phenolic compounds were mixed, the antioxidant activities of the three main compounds were lower than antioxidant activities of amino acids and phenolic compounds mixture, which also demonstrated the antagonism of organic acids. In addition, amino acids solution showed low antioxidant capacity by three methods. The antioxidant activities of amino acids and phenolic compounds were higher than those of phenolic compounds alone, indicating amino acids had synergistic effect on the antioxidant capacity of phenolic compounds. When organic acids, amino acids and phenolic compounds were mixed, the antioxidant activities of the three main compounds were higher than antioxidant activities of organic acids and phenolic compounds mixture, which also demonstrated the synergism of amino acids. In general, these data suggest that phenolic compounds showed the highest antioxidant activity among the three main compounds. Amino acids showed a synergistic effect on the antioxidant activity of phenolic compounds, while organic acids exhibited an antagonistic effect.

Table 5. Effect of main components on antioxidant activities of phenolic compounds in ZAV-5 ${ }^{1,2,3}$.

\begin{tabular}{cccc}
\hline \multirow{2}{*}{ Compositions } & \multicolumn{2}{c}{ Antioxidant Activities (mmol TEAC/g) } \\
\cline { 2 - 4 } & DPPH & ABTS & FRAP \\
\hline Organic acids & ND & ND & $0.038 \pm 0.007 \mathrm{f}$ \\
Amino acids & $0.189 \pm 0.002 \mathrm{e}$ & $0.307 \pm 0.020 \mathrm{e}$ & $0.364 \pm 0.004 \mathrm{e}$ \\
Phenolic compounds & $20.025 \pm 2.019 \mathrm{c}$ & $21.728 \pm 2.985 \mathrm{c}$ & $24.462 \pm 2.623 \mathrm{c}$ \\
Organic acids-phenolic compounds & $15.075 \pm 1.982 \mathrm{~d}$ & $14.620 \pm 1.942 \mathrm{~d}$ & $20.976 \pm 3.755 \mathrm{~d}$ \\
Amino acids-phenolic compounds & $35.203 \pm 4.361 \mathrm{a}$ & $42.371 \pm 10.418 \mathrm{a}$ & $45.574 \pm 9.325 \mathrm{a}$ \\
Organic acids-amino acids-phenolic & $31.979 \pm 6.110 \mathrm{~b}$ & $38.060 \pm 7.329 \mathrm{~b}$ & $39.635 \pm 6.927 \mathrm{~b}$ \\
compounds & & & \\
\hline
\end{tabular}

${ }^{1}$ Data are presented as mean \pm S.D. $(n=3) .{ }^{2}$ Significant differences are evaluated using the Duncan Multiple comparison Test. Different letters in the column presents statistically significant differences $(p<0.05) .{ }^{3} \mathrm{ND}$ represents not detectable. 


\subsection{Contribution of Phenolic Compounds to Antioxidant Activity in ZAV-5}

To further verify the contribution of phenolic compounds on antioxidant capacity in ZAV-5, the antioxidant activities of mixed solution were measured by three different assays. As shown in Figure 2, catechin, vanillic acid and syringic acid were the main phenolic compounds, which had high contribution rates. Catechin and vanillic acid were higher contents among these phenolic compounds and had a high contribution rate. Content of syringic acid was lower, while the contribution was higher. It may be due to the synergistic effect among the phenolic compounds. In addition, the contribution rates of the phenolic compounds in the mixed solution were far more than $100 \%$, which revealed that phenolic compounds reacted with each other had synergistic effect on the antioxidant activity. Chen et al. [37] detected that there were eight free phenolic acids in Shanxi aged vinegar. Among these phenolic compounds, except for salicylic acid or $p$-hydroxybenzoic acid with protocatechuic acid or dihydro ferulic acid showed antagonistic effect, other phenolic compounds reacted with each other and showed synergistic effect. The contribution of phenolic compounds to antioxidant activity in vinegars has been rarely reported. The results imply that contributions of phenolic compounds to antioxidant activity were not only correlated with their contents, but with synergistic effect on other compounds. More studies are needed to clarify the antioxidant components and their contribution rates to antioxidant activity of vinegar.

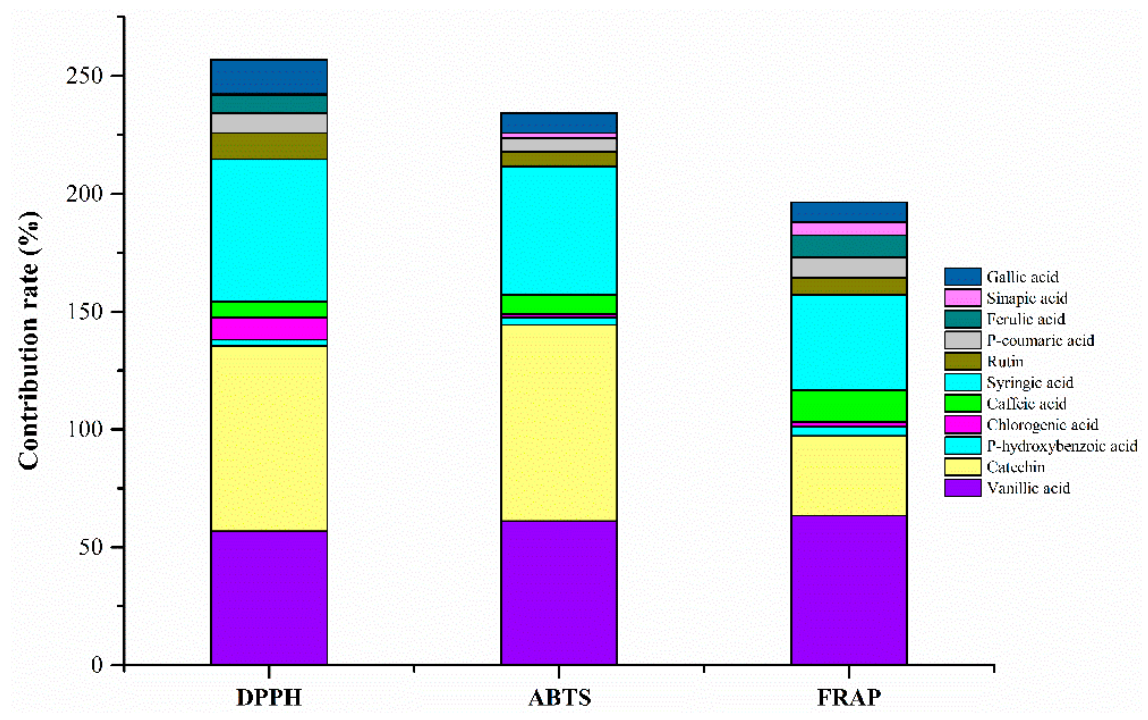

Figure 2. Contribution rate of phenolic compounds in ZAV measured by three different assays.

\section{Materials and Methods}

\subsection{Chemical Reagents and Vinegar Samples}

The FRAP and ABTS assay kits were supplied from Beyotime Institute of Biotechnology (Shanghai, China), which were used to measure antioxidant activity. Standards of organic acids and phenolic compounds were purchased from Sigma-Aldrich (Deisenhofen, Germany). Folin-Ciocalteu reagent and DPPH were purchased from Sinopharm Chemical Reagent Co., Ltd (Shanghai, China).

6 vinegar samples for each aging time $(0,3,6,8$ and 10 years) were obtained from Zhenjiang Hengshun Vinegar Co., Ltd (Jiangsu, China). The characteristics of the vinegar samples were shown in Table 6.

\subsection{Determination of the Physical and Chemical Parameters}

The $\mathrm{pH}$ values were measured using a $\mathrm{pH}$ meter (Metrohm, Herisau, Switzerland). Total acids were determined according to the GB/T 12456-2008. The contents of amino nitrogen in vinegar samples were determined by formaldehyde titration (GB/T 5009.235-2016). The reducing sugar contents in ZAV 
were calculated by Fehling's method. The contents of non-volatile organic acids and soluble solids were detected according to the methods of National Standard (GB/T18623-2011; GB/T18187-2000).

Table 6. The samples of $\mathrm{ZAV}^{1}$.

\begin{tabular}{ccc}
\hline Samples & Number & Aging Time (Year) \\
\hline ZAV-1 & 6 & 0 \\
ZAV-2 & 6 & 3 \\
ZAV-3 & 6 & 6 \\
ZAV-4 & 6 & 8 \\
ZAV-5 & 6 & 10 \\
\hline \multicolumn{2}{c}{${ }^{1}$ All the origins are in China, Jiangsu. }
\end{tabular}

\subsection{Assessment of Antioxidant Activity}

DPPH assay. Every sample was diluted 20 times with distilled water. DPPH working solution was prepared. $20 \mathrm{mg}$ of DPPH was added to $250 \mathrm{~mL}$ ethanol to make $0.2 \mathrm{mmol} / \mathrm{L} \mathrm{DPPH}$ solution. $0.2 \mathrm{mmol} / \mathrm{L}$ DPPH solution and ethanol $(5: 4, v / v)$ were mixed to make DPPH working solution. Diluted samples $(20 \mu \mathrm{L})$ were added to DPPH working solution $(180 \mu \mathrm{L})$, and the mixed solution were incubated at room temperature for $30 \mathrm{~min}$ in the dark. The absorbances of solution were measured at $517 \mathrm{~nm}$ using an automated enzyme-linked immunosorbent assay (ELISA) reader (Tecan Austria GmbH, Salzburg, Austria). The data were expressed as trolox equivalent antioxidant capacity (TEAC).

ABTS assay. The ABTS assay was performed as described by Re et al. [38] with a slight modification. Every sample was diluted 20 times with distilled water. $7 \mathrm{mM}$ ABTS solution was mixed with $2.45 \mathrm{mM}$ potassium persulfate, and then kept at room temperature in the dark for $12 \mathrm{~h}$. ABTS solution was diluted using ethanol to an absorbance of $0.70 \pm 0.10$ at $414 \mathrm{~nm} .170 \mu \mathrm{L}$ of the diluted ABTS solution was added to $10 \mu \mathrm{L}$ of an appropriately diluted sample and incubated at room temperature for $6 \mathrm{~min}$. The absorbance was recorded at a wavelength of $414 \mathrm{~nm}$ using an ELISA reader. Trolox was calculated as a standard compound. Antioxidant activity was recorded as TEAC.

FRAP assay. Every sample was diluted 20 times with distilled water. The FRAP solution was prepared by mixing $300 \mathrm{mM}$ acetate buffer, $10 \mathrm{mM}$ tripyridyltriazine (TPTZ) and $20 \mathrm{mM} \mathrm{FeCl}_{3}$ with a ratio of 10:1:1 $(v / v / v) .180 \mu \mathrm{L}$ of the FRAP working solution and $5 \mu \mathrm{L}$ of this diluted sample were mixed, and the mixture was incubated at room temperature for $5 \mathrm{~min}$. The absorbance was measured at $593 \mathrm{~nm}$. Trolox was used as a standard compound. The antioxidant activity was expressed as TEAC.

\subsection{Measurement of Organic Acids}

The organic acid contents of vinegar samples were determined by HPLC (Agilent Corp., Karlsruhe, Germany). The chromatographic column was used an Aminex HPX-87H lon Exculsion Column $\left(7.8 \times 300 \mathrm{~mm}\right.$; i.d., $5 \mu \mathrm{m}$; Shanghai, China). The mobile phase includes $\mathrm{H}_{2} \mathrm{SO}_{4}$-water $(5 \mathrm{mM})$. The injection volume was $20 \mu \mathrm{L}$, and the flow rate was $0.6 \mathrm{~mL} / \mathrm{min}$ with $30^{\circ} \mathrm{C}$ column temperature. The ultraviolet (UV) absorption was detected at $215 \mathrm{~nm}$. The identification and detection of each compound were carried by comparison of their retention times with authentic standards. $2 \mathrm{~mL}$ of diluted samples were centrifuged at $6000 \mathrm{rpm}$ for $10 \mathrm{~min}$ at a room temperature, and the supernatant was filtered through $0.45 \mu \mathrm{m}$ Millipore membrane (Billerica, MA, USA).

\subsection{Detection of Amino Acids}

Amino acid contents were analyzed by Amino Acid Analyzer (S-433D; SYKAM, Munich, Germany) equipped with a fluorescence detector. Vinegar samples were centrifuged at $7000 \mathrm{rpm}$ for $15 \mathrm{~min}$ at a room temperature, diluted 50 times with distilled water. In brief, diluted vinegar samples $(200 \mu \mathrm{L})$ and salicylic acid $(2 \%, v / v)(800 \mu \mathrm{L})$ were mixed and stood at room temperature for $30 \mathrm{~min}$. The mixture was centrifuged at 13,000 rpm for $15 \mathrm{~min}$, and the upper layer was filtered via $0.45 \mu \mathrm{m}$ Millipore membrane. LCAK06/Na $(4.6 \mathrm{~mm} \times 150 \mathrm{~mm})$ column was used for free amino acid determination. 
The working parameters were $0.45 \mathrm{~mL} / \mathrm{min}$ flow rate, $50 \mu \mathrm{L}$ injection volume and $58{ }^{\circ} \mathrm{C}$ column temperature. The ninhydrin (NIN)-derivatized amino acids were determinated at $570 \mathrm{~nm}$ and at 440 $\mathrm{nm}$. A calibration curve was prepared with different concentrations of amino acids solutions, and the results were expressed as $\mathrm{g} / \mathrm{L}$ of vinegar samples.

\subsection{Measurement of Total Phenolic and Flavonoid Contents}

Total phenolic contents of vinegar samples with different aging times were determined using the Folin-Ciocalteu method [39]. Briefly, $0.2 \mathrm{~mL}$ of an appropriately diluted sample in distilled water (1:10, $v / v$ ) and $0.8 \mathrm{~mL}$ of Folin-Ciocalten reagent were mixed and incubated in the dark for $3 \mathrm{~min}$ at room temperature. $1.5 \mathrm{~mL}$ of $10 \%$ sodium carbonate and $7.5 \mathrm{~mL}$ of distilled water were mixed and incubated for $2 \mathrm{~h}$. The absorbance was detected at $765 \mathrm{~nm}$. The data were calculated as $\mathrm{mg} \mathrm{GAE} / \mathrm{mL}$. Gallic acid was used as a standard.

The total flavonoids contents of vinegar samples were measured by the colorimetric assay. Vinegar samples were neutralized by $2 \% \mathrm{NaOH}$ solution earth firstly, and diluted 10 times with distilled water. $2.0 \mathrm{~mL}$ of diluted samples in distilled water and $1.0 \mathrm{~mL}$ of $\mathrm{NaNO}_{2}$ solution $(5 \%, w / v)$ were mixed and kept for $6 \mathrm{~min}$ at room temperature in the dark. Then, $1.0 \mathrm{~mL}$ of $\mathrm{Al}\left(\mathrm{NO}_{3}\right)_{3}$ solution $(5 \%$, w/v) was added and stood for $6 \mathrm{~min}$, and then $4.0 \mathrm{~mL}$ of $\mathrm{NaOH}$ solution $(20 \%, w / v)$ was added. The volume of mixed solution was $25.0 \mathrm{~mL}$ distilled with water and kept at room temperature for $15 \mathrm{~min}$. The absorbance was measured by a spectrophotometer at $510 \mathrm{~nm}$. The results were expressed as $\mathrm{mg} \mathrm{RE} / \mathrm{mL}$ (Rutin was used as reference).

\subsection{Determination of Phenolic Compounds}

The phenolic compounds contents were analyzed by HPLC. ZAV were extracted with ethyl acetate three times. Vinegar samples were neutralized with $\mathrm{NaOH}$ solution and mixed with ethyl acetate. The ethyl acetate layer was ultrasound and centrifuged for $10 \mathrm{~min}$, respectively. The upper layer was collected and concentrated at $35-40{ }^{\circ} \mathrm{C}$ using a vacuum rotary evaporator (Labortechnik, AG $\mathrm{CH}-9230$, Postfach, Flawil, Switzerland). Finally, the residue was dissolved in 50\% methanol (v/v). The supernatant was filtered using a $0.45 \mu \mathrm{m}$ Millipore membrane. Chromatographic condition: Phenyl chromatography column $(250 \mathrm{~mm} \times 4.6 \mathrm{~mm}$ i.d., $5 \mu \mathrm{m})$. The chromatographic conditions were showed as follows: flow rate was $1.0 \mathrm{~mL} / \mathrm{min}$; injection volume was $10 \mu \mathrm{L}$, and column temperature was $40^{\circ} \mathrm{C}$. Mobile phase: solvent A: water/acetic acid $(98: 2, v / v)$; solvent B: water/acetonitrile/acetic acid (73:25:2, $v / v / v)$ : 0-19 $\mathrm{min}, 4-5 \% \mathrm{~B} ; 46-59 \mathrm{~min}, 15-20 \% \mathrm{~B}$; 59-61 $\mathrm{min}, 10-20 \% \mathrm{~B}, 64 \mathrm{~min}, 5 \% \mathrm{~B}$ and then held for 5 min. The UV absorption was detected at $278 \mathrm{~nm}$.

\subsection{Examination of Antioxidant Activities in Phenolic Mixed Solution}

According to the contents of phenolic compounds measured by HPLC, the model solution of phenolic compounds was prepared with standard substances. A kind of phenolic compound was deleted from the model solution, and then antioxidant activities of residual solution were determined by DPPH, ABTS and FRAP methods. The results were calculated as follows: Contribution rate of missing substance $(\%)=(($ Antioxidant value of model solution - antioxidant value of residual solution)/Antioxidant value of model solution) $\times 100 \%$.

\subsection{Statistical Analysis}

Results were presented as mean \pm standard deviation (S.D.). Variance analysis was carried by duncan multiple comparison test using the SPSS statistical package version 24.0 software (SPSS Inc., Chicago, IL, USA). $p<0.05$ suggested significant differences. 


\section{Conclusions}

In the present study, physicochemical properties, organic acids, amino acids, phenolic compounds, and antioxidant characteristic of ZAV were investigated. The results showed that the contents of total acids, soluble solids, reducing sugar and total antioxidant activity in ZAV were increased with aging time, and highest in ZAV-5. In addition, acetic acid, lactic acid and pyroglutamic acid were the main organic acids, and leucine, glycine and threonine were the main amino acids in ZAV-5. Organic acids and amino acids both contributed weakly to total antioxidant activity of ZAV-5. Catechin, $p$-hydroxybenzoic acid and vanillic acid were the major phenolic compounds in ZAV-5. Phenolic compounds exhibited high antioxidant activity such as caffeic acid, gallic acid, sinapic acid, syringic acid, catechin, rutin, and ferulic acid. Furthermore, amino acids showed synergistic effect on the antioxidant activity of phenolic compounds, while organic acids exhibited antagonistic effect on the antioxidant activity of phenolic compounds. Catechin, vanillic acid and syringic acid had high contribution rates to the antioxidant activity of mixed phenolic compounds.

Author Contributions: Conceptualization, B.Z. and T.X.; Formal analysis, W.D.; Investigation, Z.Z. and Y.L.; Resources B.F. and M.X.; Supervision, T.X., and M.W.; Validation, M.W.; Writing-original draft, B.Z. and T.X.; Writing-review and editing, B.Z. and T.X.

Funding: This research was funded by the National Natural Science Foundation of China (81600126), the National Key R\&D Program of China (2016YFD0400505), Tianjin Municipal Education Commission (TD13-5013), Open Project Program of State Key Laboratory of Food Nutrition and Safety, Tianjin University of Science \& Technology (No. SKLFNS-KF-201818), and Tianjin Municipal Education Commission (2017KJ009).

Conflicts of Interest: The authors declare no conflict of interest.

\section{Abbreviations}

$\begin{array}{ll}\text { ZAV } & \text { Zhenjiang aromatic vinegar } \\ \text { ABTS } & \text { 2,2'-azino-bis(3-ethylbenzthiazoline-6-sulfonic acid } \\ \text { DPPH } & \text { 2,2-diphenyl-1-picrylhydrazyl } \\ \text { FRAP } & \text { ferric reducing antioxidant power } \\ \text { HPLC } & \text { high performance liquid chromatography } \\ \text { IC } & \text { ion liquid chromatography } \\ \text { NMR } & \text { nuclear magnetic resonance } \\ \text { UPLC-MS } & \text { ultra-performance liquid chromatography-mass spectrum } \\ \text { TBV } & \text { traditional balsamic vinegar } \\ \text { TEAC } & \text { trolox equivalent antioxidant capacity }\end{array}$

\section{References}

1. Solieri, L.; Giudici, P. Vinegars of the World; Springer: Milan, Italy, 2009; pp. 1-16.

2. Liu, D.R.; Zhu, Y.; Beeftink, R.; Ooijkaas, L.; Rinzema, A.; Chen, J.; Tramper, J. Chinese vinegar and its solid-state fermentation process. Food Rev. Int. 2004, 20, 407-424. [CrossRef]

3. Koyama, M.; Ogasawara, Y.; Endou, K.; Akano, H.; Nakajima, T.; Aoyama, T.; Nakamura, K. Fermentationinduced changes in the concentrations of organic acids, amino acids, sugars, and minerals and superoxide dismutase-like activity in tomato vinegar. Int. J. Food Prop. 2017, 20, 888-898. [CrossRef]

4. Xu, W.; Huang, Z.; Zhang, X.; Li, Q.; Lu, Z.; Shi, J.; Xu, Z.; Ma, Y. Monitoring the microbial community during solid-state acetic acid fermentation of Zhenjiang aromatic vinegar. Food Microbiol. 2011, 28, 1175-1181. [CrossRef] [PubMed]

5. Zhao, C.Y.; Xia, T.; Du, P.; Duan, W.H.; Zhang, B.; Zhang, J.; Zhu, S.H.; Zheng, Y.; Wang, M.; Yu, Y.J. Chemical composition and antioxidant characteristic of traditional and industrial Zhenjiang aromatic vinegars during the aging process. Molecules 2018, 23, 2949. [CrossRef]

6. Yamashita, H. Biological function of acetic acid-improvement in obesity and glucose tolerance by acetic acid in type 2 diabetic rats. Crit. Rev. Food Sci. Nutr. 2015, 56, S171-S175. [CrossRef]

7. Ren, W.; Liu, G.; Yin, J.; Tan, B.; Wu, G.; Bazer, F.W.; Peng, Y.; Yin, Y. Amino-acid transporters in T-cell activation and differentiation. Cell Death Dis. 2017, 8, e2655. [CrossRef] 
8. Ferreira, S.S.; Passos, C.P.; Madureira, P.; Vilanova, M.; Coimbra, M.A. Structure-function relationships of immunostimulatory polysacch arides: A review. Carbohyd. Polym. 2015, 132, 378-396. [CrossRef]

9. Ho, C.W.; Lazim, A.M.; Fazry, S.; Zaki, U.K.; Lim, S.J. Varieties, production, composition and health benefits of vinegars: A review. Food Chem. 2017, 221, 1621-1630. [CrossRef]

10. Zhu, H.; Zhu, J.; Wang, L.; Li, Z. Development of a SPME-GC-MS method for the determination of volatile compounds in Shanxi aged vinegar and its analytical characterization by aroma wheel. J. Food Sci. Technol. 2016, 53, 171-183. [CrossRef]

11. Shi, J.Y.; Zou, X.B.; Huang, X.W.; Zhao, J.W.; Li, Y.X.; Hao, L.M.; Zhang, J.C. Rapid detecting total acid content and classifying different types of vinegar based on near infrared spectroscopy and least-squares support vector machine. Food Chem. 2013, 138, 192-199.

12. Cocchi, M.; Durante, C.; Grandi, M.; Lambertini, P.; Manzini, D.; Marchetti, A. Simultaneous determination of sugars and organic acids in aged vinegars and chemometric data analysis. Talanta 2006, 69, 1166-1175. [CrossRef] [PubMed]

13. Wang, Z.; Li, T.; Liu, F.; Zhang, C.; Ma, H.; Wang, L.; Zhao, S. Effects of ultrasonic treatment on the maturation of Zhenjiang vinegar. Ultrason. Sonochem. 2017, 39, 272-280. [CrossRef] [PubMed]

14. Liu, F.; He, Y. Application of successive projections algorithm for variable selection to determine organic acids of plum vinegar. Food Chem. 2009, 115, 1430-1436. [CrossRef]

15. Sáiz-Abajo, M.J.; González-Sáiz, J.M.; Pizarro, C. Prediction of organic acids and other quality parameters of wine vinegar by near-infrared spectroscopy. A feasibility study. Food Chem. 2006, 99, 615-621. [CrossRef]

16. Maestre, O.; Santos-Dueñas, I.M.; Peinado, R.; Jiménez-Ot, C.; García-García, I.; Mauricio, J.C. Changes in amino acid composition during wine vinegar production in a fully automatic pilot acetator. Process Biochem. 2008, 43, 803-807. [CrossRef]

17. Chen, T.; Gui, Q.; Shi, J.J.; Zhang, X.Y.; Chen, F.S. Analysis of variation of main components during aging process of Shanxi aged vinegar. Acetic Acid Bact. 2013, 2, 6. [CrossRef]

18. Álvarez-Cáliz, C.; Santos-Duenas, I.M.; Canete-Rodríguez, A.M.; Garcí-Martínez, T.; Mauricio, J.C.; García-García, I. Free amino acids, urea an ammonium ion contents for submerged wine vinegar production: Influence of loading rate and air-flow rate. Acetic Acid Bact. 2012, 1, e1.

19. Kong, Y.; Zhang, L.L.; Sun, Y.; Zhang, Y.Y.; Sun, B.G.; Chen, H.T. Determination of the free amino acid, organic acid, and nucleotide in commercial vinegars. J. Food Sci. 2017, 82, 1116-1123. [CrossRef]

20. Massey, K.A.; Blakeslee, C.H.; Pitkow, H.S. A review of physiological and metabolic effects of essential amino acids. Amino Acids (Vienna) 1998, 14, 271-300. [CrossRef]

21. Brosnan, J.T.; Brosnan, M.E. The sulfur-containing amino acids: An overview. J. Nutr. 2006, 136, 1636S-1640S. [CrossRef]

22. Morozova, O.B.; Yurkovskaya, A.V. Modulation of the rate of reversible electron transfer in oxidized tryptophan and tyrosine containing peptides in acidic aqueous solution. J. Phys. Chem. B. 2015, 119, 140-149. [CrossRef] [PubMed]

23. Chen, H.Y.; Chen, T.; Giudici, P.; Chen, F.S. Vinegar functions on health: Constituents, sources, and formation mechanisms. Compr. Rev. Food Sci. Food Saf. 2016, 15, 1124-1138. [CrossRef]

24. Rice-Evans, C.A.; Miller, N.J.; Paganga, G. Structure-antioxidant activity relationships of flavonoids and phenolic acids. Free Radic. Biol. Med. 1996, 20, 933-956. [CrossRef]

25. Treml, J.; Šmejkal, K. Flavonoids as potent scavengers of hydroxyl radicals. Compr. Rev. Food Sci. Food Saf. 2016, 15, 720-738. [CrossRef]

26. Tagliazucchi, D.; Verzelloni, E.; Conte, A. Antioxidant properties of traditional balsamic vinegar and boiled must model systems. Eur. Food Res. Technol. 2008, 227, 835-843. [CrossRef]

27. Xia, T.; Yao, J.H.; Zhang, J.; Duan, W.H.; Zhang, B.; Xie, X.L.; Xia, M.L.; Song, J.; Zheng, Y.; Wang, M. Evaluation of nutritional compositions, bioactive compounds, and antioxidant activities of Shanxi aged vinegars during the aging process. J. Food Sci. 2018, 83, 2638-2644. [CrossRef]

28. Xie, X.L.; Zheng, Y.; Liu, X.; Cheng, C.; Zhang, X.L.; Xia, T.; Yu, S.F.; Wang, M. Antioxidant activity of Chinese Shanxi aged vinegar and its correlation with polyphenols and flavonoids during the brewing process. J. Food Sci. 2017, 82, 2479-2486. [CrossRef]

29. Bakir, S.; Toydemir, G.; Boyacioglu, D.; Beekwilder, J.; Capanoglu, E. Fruit antioxidants during vinegar processing: Changes in content and in vitro bio-accessibility. Int. J. Mol. Sci. 2016, 17, 1658. [CrossRef] 
30. Verzelloni, E.; Tagliazucchi, D.; Conte, A. Relationship between the antioxidant properties and the phenolic and flavonoid content in traditional balsamic vinegar. Food Chem. 2007, 105, 564-571. [CrossRef]

31. Xia, T.; Yao, J.H.; Zhang, J.; Zheng, Y.; Song, J.; Wang, M. Protective effects of Shanxi aged vinegar against hydrogen peroxide-induced oxidative damage in LO2 cells through Nrf2-mediated antioxidant responses. RSC Adv. 2017, 7, 17377-17386. [CrossRef]

32. Kim, S.H.; Cho, H.K.; Shin, H.S. Physicochemical properties and antioxidant activities of commercial vinegar drinks in Korea. Food Sci. Biotechnol. 2012, 21, 1729-1734. [CrossRef]

33. Bertelli, D.; Maietti, A.; Papotti, G.; Tedeschi, P.; Bonetti, G.; Graziosi, R.; Brandolini, V.; Plessi, M. Antioxidant activity, phenolic compounds, and NMR characterization of balsamic and traditional balsamic vinegar of Modena. Food Anal. Method 2015, 8, 371-379. [CrossRef]

34. Lalou, S.; Hatzidimitriou, E.; Papadopoulou, M.; Kontogianni, V.G.; Tsiafoulis, C.G.; Gerothanassis, L.P.; Tsimidou, M.Z. Beyond traditional balsamic vinegar: Compositional and sensorial characteristics of industrial balsamic vinegars and regulatory requirements. J. Food Compos. Anal. 2015, 43, 175-184. [CrossRef]

35. Chinnici, F.; Durán-Guerrero, E.; Riponi, C. Discrimination of some European vinegars with protected denomination of origin as a function of their amino acid and biogenic amine content. J. Sci. Food Agr. 2015, 96, 3762-3771. [CrossRef] [PubMed]

36. Kharchoufi, S.; Gomez, J.; Lasanta, C.; Castro, R.; Sainz, F.; Hamdi, M. Benchmarking laboratory-scale pomegranate vinegar against commercial wine vinegars: Antioxidant activity and chemical composition. J. Sci. Food Agric. 2018, 98, 4749-4758. [CrossRef]

37. Chen, H.Y.; Zhou, Y.X.; Shao, Y.C.; Chen, F.S. Free phenolic acids in Shanxi aged vinegar: Changes during aging and synergistic antioxidant activities. Int. J. Food Prop. 2015, 19, 1183-1193. [CrossRef]

38. Re, R.; Pellegrini, N.; Proteggente, A.; Pannala, A.; Yang, M.; Rice-Evans, C. Antioxidant activity applying an improved ABTS radical cation decolorization assay. Free Radic. Biol. Med. 1999, 26, 1231-1237. [CrossRef]

39. Kumazawa, S.; Taniguchi, M.; Suzuki, Y.; Shimura, M.; Kwon, M.S.; Nakayama, T. Antioxidant activity of polyphenols in carob pods. J. Agric. Food Chem. 2002, 50, 373-377. [CrossRef]

Sample Availability: Samples of the Zhenjiang aromatic vinegars are available from the authors.

(C) 2019 by the authors. Licensee MDPI, Basel, Switzerland. This article is an open access article distributed under the terms and conditions of the Creative Commons Attribution (CC BY) license (http://creativecommons.org/licenses/by/4.0/). 